\title{
Rigid bronchoscopy under intravenous general anaesthesia with oxygen Venturi ventilation
}

\author{
DJ GODDEN, RF WILLEY, RJ FERGUSSON, DJ WRIGHT, GK CROMPTON, IWB GRANT
}

From the Respiratory Unit, Northern General Hospital, Edinburgh, and the Departments of Medicine and Anaesthetics, Western General Hospital, Edinburgh

\begin{abstract}
In a study of 100 patients undergoing rigid bronchoscopy under intravenous general anaesthesia with oxygen Venturi ventilation no major complications were observed. Minor complications included one adverse reaction to alphaxalone-alphadolone acetate (Althesin), one prolonged episode of laryngeal spasm after removal of the bronchoscope, and subsequent muscle pain attributed to suxamethonium in 36 patients. The last complication occurred significantly less frequently $(p<0.025)$ in those patients who were pretreated with a small dose of a nondepolarising neuromuscular blocking agent. Serial arterial blood gas sampling in 10 patients showed adequate ventilation during bronchoscopy, but carbon dioxide retention developed in nine cases immediately after the bronchoscope was withdrawn. With adequate precautions, however, the procedure is safe and well tolerated, even in patients with severe impairment of respiratory function.
\end{abstract}

Since 1974 intravenous general anaesthesia, with oxygen Venturi ventilation, has replaced local anaesthesia for rigid bronchoscopy at the Northern and Western General Hospitals in Edinburgh. Over 1500 such procedures have been performed in the past seven years with no deaths and with an apparently low complication rate, considering the high anaesthetic risk presented by many of the patients. A detailed prospective study of 100 consecutive outpatient bronchoscopic examinations was carried out to assess more accurately the incidence of complications.

\section{Methods}

High-concentration oxygen was administered for five minutes before induction of anaesthesia with an intravenous agent. Suxamethonium chloride was also injected intravenously to produce neuromuscular blockade. A rigid bronchoscope was then introduced, and the patient was ventilated by the Venturi technique with a manual control system, additional doses of anaesthetic and suxamethonium being given as required. The electrocardiogram was monitored throughout the procedure. Endotracheal intu-

Address for reprint requests: Dr GK Crompton, Respiratory Unit, Northern General Hospital, Edinburgh EH5 2DQ. bation was not routinely performed after removal of the bronchoscope, but close clinical supervision was maintained during the recovery phase.

Assessment before bronchoscopy included grading of breathlessness; ${ }^{1}$ measurement of forced expiratory volume in one second $\left(\mathrm{FEV}_{1}\right)$ and forced vital capacity (FVC); and, when considered necessary on clinical grounds, arterial blood gas analysis. Details of any complications during and after bronchoscopy were recorded. All patients were supplied with a postcard to report the occurrence of subsequent muscle pain.

In 10 patients, randomly selected and with their informed consent, a radial artery cannula was inserted, and serial blood gas measurements were made throughout the procedure and for 15 minutes after removal of the bronchoscope. The partial pressures of oxygen $\left(\mathrm{PaO}_{2}\right)$ and carbon dioxide $\left(\mathrm{PaCO}_{2}\right)$ and the hydrogen ion concentration of the various samples were measured with a Radiometer ABL2 blood gas analyser.

\section{Patients}

The 100 outpatients in the study comprised 77 men and 23 women, with a mean age of 63 years (range 25-81). There were 80 smokers, 5 ex-smokers and 12 non-smokers (smoking habits not known in 
three). The principal diagnosis was bronchial carcinoma in 60 cases, unexplained haemoptysis in 16 , pneumonia in nine, chronic bronchitis in seven, metastatic carcinoma in two, and bronchiectasis in two. There were single cases of intralobar sequestration, unilateral emphysema, pulmonary fibrosis, and pulmonary thromboembolism. The whole group included nine patients with clinical evidence of ischaemic heart disease (four with angina, three with atrial fibrillation, and two with a previous history of myocardial infarction), seven with superior vena caval obstruction, five with stridor, two with carbon dioxide retention, and one with hypopituitarism.

Atropine sulphate (up to $0.6 \mathrm{mg}$ intravenously) was given to 41 patients immediately before the induction of anaesthesia. In 76 patients anaesthesia was induced and maintained with thiopentone sodium (mean total dose $496 \mathrm{mg}$ ), in 21 with Althesin (mean total dose $7.1 \mathrm{ml}$ ), and in two with methohexitone sodium. One patient, after an adverse reaction to Althesin $(1 \mathrm{ml})$, was subsequently anaesthetised with thiopentone. All patients were given suxamethonium intravenously, and in 26 of them small doses of a non-depolarising agent (gallamine in 25 cases and pancuronium in one case) were injected 10-30 seconds earlier. The mean total dose of suxamethonium was $153 \mathrm{mg}$ (range 50-400 $\mathrm{mg}$ ).

\section{Results}

\section{ASSESSMENT BEFORE BRONCHOSCOPY}

Grading of dyspnoea showed that 41 patients had grade 1,19 grade 2, 15 grade 3,16 grade 4 , and 8 grade 5 (in one case the grade was unknown). Thus $24 \%$ of patients were severely disabled (grades 4 and 5). On spirometry the mean $\mathrm{FEV}_{1}$ was 1.81 (range 0.4-3.6) and the mean FVC 2.7 1 (range $0 \cdot 5-5 \cdot 1$ ). Arterial blood gas analysis was carried out in 51 cases. The mean $\mathrm{PaO}_{2}$ was $9.9 \mathrm{kPa}$ (range $7 \cdot 6-15 \cdot 1 \mathrm{kPa})$ (74 and 57-113 $\mathrm{mm} \mathrm{Hg}$ ), the mean
$\mathrm{PaCO}_{2} 5.0 \mathrm{kPa}$ (range $\left.3 \cdot 8-6.4 \mathrm{kPa}\right)(37$ and $28-48 \mathrm{~mm}$ $\mathrm{Hg}$ ), and the mean hydrogen ion concentration 37 $\mu \mathrm{mol} / 1$ (range 29.5-42).

\section{COMPLICATIONS}

During bronchoscopy In our experience, copious, thick secretions may prevent adequate ventilation with a Venturi system, but this complication was not encountered in the 100 patients studied. The five patients with stridor presented no problems with ventilation. Superior vena caval obstruction caused some difficulties for the anaesthetist in that the intravenous agents had to be injected into a vein in a lower limb, and the longer circulation time made it less easy to control anaesthesia and muscle paralysis.

After bronchoscopy One patient suffered a prolonged episode of laryngeal spasm after removal of the bronchoscope, but there were no other complications immediately after the procedure. According to postcard replies from 92 patients, 36 (39\%) experienced muscle pains-lasting for less than one day in 12 cases, but for two days in 18 cases, three days in two cases, four days in three cases, and 10 days in one case. Of the 26 patients who received a small additional dose of a non-depolarising agent, only five (19\%) reported muscle pain. In the group given suxamethonium alone, however, 31 (47\%) reported pain. The lower incidence of pain when a non-depolarising agent was given before administration of suxamethonium was statistically significant ( $p$ $<0.025)$. There was no relationship between the incidence of muscle pains and the type of drug used to induce anaesthesia.

\section{ARTERIAL BLOOD GAS STUDIES}

The mean values for $\mathrm{PaO}_{2}, \mathrm{PaCO}_{2}$, and hydrogen ion concentration recorded at specified stages of the investigation in 10 patients are shown in the table. Oxygenation was adequate throughout the examination and after removal of the bronchoscope, with all

Arterial blood gas changes (means with ranges in parentheses) in 10 randomly selected patients at defined periods

\begin{tabular}{|c|c|c|c|}
\hline Time & $\begin{array}{l}\mathrm{PO}_{2} \\
(k P a)\end{array}$ & $\begin{array}{l}\mathrm{PCO}_{2} \\
(\mathrm{kPa})\end{array}$ & $\begin{array}{l}H^{+} \\
(\mathrm{nmol} / \mathrm{l})\end{array}$ \\
\hline $\begin{array}{l}\text { Before procedure } \\
\text { Before insertion of bronchoscope (after preoxygenation) } \\
\text { Mid-procedure } \\
\text { Immediately after removal of bronchoscope } \\
\text { Five minutes after removal of bronchoscope } \\
\text { Ten minutes after removal of bronchoscope }\end{array}$ & $\begin{array}{l}10 \cdot 0 \\
(7 \cdot 4-14 \cdot 3) \\
33 \cdot 5 \\
(25 \cdot 5-49 \cdot 7) \\
44 \cdot 5 \\
(31 \cdot 9-58 \cdot 9) \\
33 \cdot 2 \\
(12 \cdot 6-56 \cdot 0) \\
22 \cdot 5 \\
(10 \cdot 1-36 \cdot 3) \\
18 \cdot 0 \\
(8 \cdot 8-22 \cdot 3)\end{array}$ & $\begin{array}{l}5 \cdot 1 \\
(4 \cdot 4-6 \cdot 7) \\
5 \cdot 8 \\
(4 \cdot 9-6 \cdot 7) \\
4 \cdot 9 \\
(4 \cdot 1-6 \cdot 7) \\
6 \cdot 4 \\
(4 \cdot 9-8 \cdot 4) \\
7 \cdot 0 \\
(4 \cdot 6-10 \cdot 0) \\
6 \cdot 8 \\
(4 \cdot 4-7 \cdot 7)\end{array}$ & $\begin{array}{l}38 \\
(37-43) \\
42 \\
(37-44) \\
40 \\
(31-45) \\
45 \\
(35-56) \\
49 \\
(39-61) \\
48 \\
(37-54)\end{array}$ \\
\hline
\end{tabular}


$\mathrm{PaO}_{2}$ values above $8.4 \mathrm{kPa}(63 \mathrm{~mm} \mathrm{Hg})$; but eight patients had a $\mathrm{PaCO}_{2}$ over $6 \mathrm{kPa}(45 \mathrm{~mm} \mathrm{Hg}$ ) (in one as high as $10.0 \mathrm{kPa})(75 \mathrm{~mm} \mathrm{Hg})$ after removal of the bronchoscope.

\section{Discussion}

The technique of Venturi ventilation, originally described by Sanders in $1967,{ }^{2}$ represented a major advance in diagnostic rigid bronchoscopy. The method provides an effective means of ventilation without interfering with instrumentation or suction, and allows the examination to be performed quickly and efficiently. In our experience of over 1500 cases there have been no deaths attributable to the procedure, although two patients have required postoperative artificial ventilation for short periods, and in two cases it proved impossible to achieve adequate ventilation by the Venturi method until copious thick secretions had been aspirated.

Cardiac dysrhythmias are uncommon with the Venturi technique, ${ }^{3}$ and the only dysrhythmias observed on continuous electrocardiographic monitoring of the 100 patients in this study were occasional extrasystoles, usually ventricular. Serial arterial blood gas measurements in 10 patients confirmed previous observations ${ }^{45}$ that adequate ventilation and oxygenation can be achieved with the Venturi technique. Carbon dioxide retention occurred, however, in eight of these 10 patients after removal of the bronchoscope, probably as a consequence of the residual effect of both the anaesthetic and the neuromuscular blocking agents. This phase would therefore appear to be potentially the most hazardous part of the procedure, and continuous close observation is required until the patient has fully recovered.

Although a few patients had a vague recollection of the examination, not one of the 100 studied prospectively was disturbed or alarmed by it; complaint is more common in patients submitted to fibreoptic bronchoscopy under local anaesthesia, especially those with impaired pulmonary function. The acceptability of rigid bronchoscopy under general anaesthesia was, however, reduced by the high incidence of muscle pain after the administration of suxamethonium. This phenomenon, first described in 1952,6 occurs more frequently if patients do not rest for a few hours afterwards. ${ }^{7}$ A considerable reduction in the incidence of pain has been observed in patients given a single dose of a non-depolarising neuromuscular blocking agent one minute before suxamethonium. ${ }^{8}$ The incidence of pain reported in our series would probably have been much lower if non-depolarising neuromuscular blocking agents, administered a full minute instead of only 10-30 seconds before suxamethonium, had been given in every case, and if the patients have been more firmly instructed to take as little exercise as possible for a few hours after recovery from the anaesthetic. Such advice, however, was often difficult for outpatients to follow.

With appropriate safeguards and expert anaesthetic supervision, general anaesthesia with oxygen Venturi ventilation provides a safe, efficient, and well-tolerated method for anaesthetising and ventilating patients during rigid bronchoscopy.

Members of the staff of the department of anaesthetics at the Western General Hospital administered all the anaesthetics reported in this study, and we gratefully acknowledge both their clinical skill and their careful documentation. Our thanks are also due to Miss Allison Gillespie for secretarial assistance.

\section{References}

${ }^{1}$ Fletcher CM. The clinical diagnosis of pulmonary emphysema. Proc Roy Soc Med 1952;45:577-84.

${ }^{2}$ Sanders RD. Two ventilating attachments for bronchoscopes. Del Med J 1967;39:170-92.

${ }^{3}$ Jenkins AV. Electrocardiographic findings during bronchoscopy: use of the Sanders technique. Anaesthesia 1976;31:548-55.

${ }^{4}$ Spoeral WE, Grant PA. Ventilation during bronchoscopy. Canadian Anaesthetists Society Journal 1971;18:178-88.

${ }^{5}$ Fuller WR, Davies DM, Stradling P. Anaesthesia for bronchoscopy prolonged by teaching and photography. Anaesthesia 1972;27:292-9.

6 Bourne JG, Collier HOJ, Somers GF. Succinylcholine: muscle relaxant of short action. Lancet 1952;1:12259.

7 Churchill-Davidson MC. Suxamethonium (succinylcholine) chloride and muscle pains. $\mathrm{Br} \mathrm{Med} J$ 1954;i:74-5.

${ }^{8}$ Collier C. Suxamethonium pains and fasciculations. Proc Roy Soc Med 1975;68:105-8. 